\title{
Dendritic signaling in inhibitory interneurons: local tuning via group I metabotropic glutamate receptors
}

\section{Olivier Camiré ${ }^{1}$, Jean-Claude Lacaille ${ }^{2}$ and Lisa Topolnik ${ }^{1}{ }^{*}$}

' Department of Biochemistry, Microbiology and Bioinformatics, Axis of Cellular and Molecular Neuroscience, CRIUSMQ, Université Laval, Québec, PQ, Canada

${ }^{2}$ Département de Physiologie and Groupe de Recherche sur le Système Nerveux Central, Université de Montréal, Montréal, PQ, Canada

\author{
Edited by: \\ Francisco Fernandez De-Miguel, \\ Universidad Nacional Autonoma de \\ Mexico, Mexico \\ Reviewed by: \\ Harald Janovjak, Institute of Science \\ and Technology Austria, Austria \\ Enrique Hernandez-Lemus, National \\ Institute of Genomic Medicine, \\ Mexico \\ ${ }^{*}$ Correspondence: \\ Lisa Topolnik, Department of \\ Biochemistry, Microbiology and \\ Bioinformatics, Axis of Cellular and \\ Molecular Neuroscience, CRIUSMO, \\ Université Laval, 2601 Ch. De La \\ Canardière, CRULRG, Québec, $P Q$, \\ Canada G1J 2 G3. \\ e-mail: lisa.topolnik@crulrg.ulaval.ca
}

Communication between neurons is achieved by rapid signal transduction via highly specialized structural elements known as synaptic contacts. In addition, numerous extrasynaptic mechanisms provide a flexible platform for the local regulation of synaptic signals. For example, peri- and extra-synaptic signaling through the group I metabotropic glutamate receptors (mGluRs) can be involved in the highly compartmentalized regulation of dendritic ion conductances, the induction of input-specific synaptic plasticity, and the local release of retrograde messengers. Therefore, extrasynaptic mechanisms appear to play a key role in the local tuning of dendritic computations. Here, we review recent findings on the role of group I mGluRs in the dendritic signaling of inhibitory interneurons. We propose that group I mGluRs provide a dual-mode signaling device that integrates different patterns of neural activity. By implementing distinct forms of intrinsic and synaptic regulation, group I mGluRs may be responsible for the local fine-tuning of dendritic function.

Keywords: GABAergic interneuron, dendrite, synapse, ion channel, plasticity, metabotropic glutamate receptor

\section{INTRODUCTION}

Over a century ago, Santiago Ramón y Cajal postulated the law of dynamic polarization, according to which dendrites represent the receiving apparatus of the neuron (Ramón y Cajal, 1891) that integrates the vast majority of synaptic inputs over time. Since then, dendrites have captured the imagination of many researchers. It is difficult not to marvel at the wide diversity and complexity of dendritic arbors, which resemble distinct kinds of trees in a forest. In addition to their morphological complexity, dendrites exhibit a highly complex functional organization. They are endowed with multiple active ion conductances, which control the integration and propagation of local and global dendritic signals in a highly dynamic manner. Two types of signals are generated in dendrites: electrical and chemical. Both can be compartmentalized within individual dendritic branches, providing a means for the synapsespecific integration and modification of incoming information (reviewed in Branco and Häusser, 2010). GABAergic inhibitory interneurons are well known for their heterogeneity at multiple levels, from structural and physiological properties to their corresponding functions in the network. Not surprisingly, interneuron dendrites also exhibit a highly heterogeneous and complex functional organization, which is determined largely by the cell type, the incoming input, and the patterns of ongoing activity. It has been established that an average hippocampal interneuron may receive up to 17,000 synaptic inputs (Gulyás et al., 1999). In addition, a large repertoire of extrasynaptic mechanisms respond to local changes in activity and allow the efficient control of synaptic integration and signal transduction. These mechanisms involve the activation of extrasynaptic glutamate, GABA, acetylcholine, and monoamine and peptide receptors, which can be located in the presynaptic terminals, dendrites, and astrocytes. The mechanisms underlying extrasynaptic signaling in interneurons and its functional role in the modulation of local circuit activity are currently under intensive investigation.

Here, we review recent work that supports the idea that the integrative properties of interneuron dendrites are controlled via activation of group I metabotropic glutamate receptors (mGluRs), which orchestrate a variety of local processes, including calcium signaling, modulation of specific ion conductances, and several forms of synaptic plasticity (Perez et al., 2001; Lapointe et al., 2003; Topolnik et al., 2006, 2009; Galván et al., 2008; Le Duigou and Kullmann, 2011). As local modulation of dendritic function is important for single neuron computations, defining the factors that control dendritic signaling in interneurons will be crucial to understanding interneuron computations. It is not our intention to discuss the important role of group I mGluRs in the regulation of network activity and in different disease states as these topics have been deeply explored in several recent reviews (Nistri et al., 2006; Bartos et al., 2007; Topolnik and Lacaille, 2009; Ribeiro et al., 2010).

\section{INTEGRATIVE PROPERTIES OF INTERNEURON DENDRITES}

As in most neurons, the synaptic inputs received by interneuron dendrites are transformed into electrical signals and conducted to the soma. The degree of the signal propagation and its impact on neuronal output are determined by the dendritic architecture and the passive and active properties of dendrites (Geiger et al., 1997; Emri et al., 2001; Nörenberg et al., 2010). In addition, the amplitude and temporal summation of excitatory postsynaptic potentials (EPSPs) are controlled via the activation of local ion 
conductances, which are often distributed non-uniformly along the somatodendritic axis. For example, direct recordings from dendrites of dentate gyrus basket cells (BCs) and hippocampal Cornu Ammonis 1 (CA1) oriens-lacunosum-moleculare (O-LMs) interneurons revealed a relatively constant density of dendritic $\mathrm{K}^{+}$channels (Martina et al., 2000; Hu et al., 2010). The activation of these channels during synaptic depolarization can speed up the time course of EPSPs and, therefore, control the temporal summation of synaptic inputs and the time window for spike generation in interneurons (Fricker and Miles, 2000; Galarreta and Hestrin, 2001). Furthermore, distinct distribution of dendritic $\mathrm{Na}^{+}$channels in BCs vs O-LMs can also affect the amplification of sub-threshold synaptic inputs and spike initiation and propagation. For example, a steep distance-dependent decay of $\mathrm{Na}^{+}$ channels is found in dendrites of BCs. Accordingly, $\mathrm{Na}^{+}$spikes can only be initiated in the $\mathrm{BC}$ axon but not in its dendrites (Hu et al., 2010). The situation is different however in O-LM interneurons. The estimated density of $\mathrm{Na}^{+}$channels in these cells is threefold larger than in pyramidal cell dendrites (Stuart and Sakmann, 1994; Martina et al., 2000). Accordingly, $\mathrm{Na}^{+}$spikes can be initiated in dendritic sites and can propagate over somatodendritic domain with a relatively constant amplitude and time course.

The propagation of an action potential into neuronal dendrites has a major impact on synaptic input integration and plasticity. These functions of the backpropagating action potential (bAP) are associated with significant depolarization and calcium $\left(\mathrm{Ca}^{2+}\right)$ entry resulting from the activation of voltage-gated $\mathrm{Ca}^{2+}$ mechanisms. The properties of bAP-evoked $\mathrm{Ca}^{2+}$ transients (bAP-CaTs) vary between types of neurons, depending on dendritic geometry, the properties and the availability of dendritic voltage-gated channels, the endogenous $\mathrm{Ca}^{2+}$-binding capacity, and level of activity (Kaiser et al., 2001; Sabatini et al., 2002; Goldberg et al., 2003a; Aponte et al., 2008; Evstratova et al., 2011). However, in most GABAergic interneurons, bAP-CaTs are largely attenuated with distance from the soma (Kaiser et al., 2001; Goldberg et al., 2003a; Evstratova et al., 2011). What can be the factors responsible for such proximal compartmentalization of bAP-CaTs? First, as in most neurons, backpropagation of APs in interneurons is likely to be decremental because of dendritic geometry (Rall, 1964; Goldstein and Rall, 1974; Spruston et al., 1995). The complex dendritic profile of most interneurons, with extensive branching close to the soma, may affect the shape of bAPs and result in rapid branchdependent bAP attenuation (Rall, 1964; Vetter et al., 2001). Second, the differential subcellular distribution of active conductances and their activity-dependent regulation via extrasynaptic mechanisms play an important role in AP backpropagation (Frick et al., 2004; Sjöström and Häusser, 2006; Hu et al., 2010). Because in most interneurons spike propagation is restricted within proximal dendritic branches, the spike-timing-dependent plasticity regulated by bAPs is likely to occur predominantly at proximal synapses. This raises an important question: what kind of associative signal may operate in distally located synapses of interneurons? One possibility is that local $\mathrm{Ca}^{2+}$ spikes can control cooperative plasticity in distal dendrites. $\mathrm{Ca}^{2+}$ regenerative events (e.g., $\mathrm{Ca}^{2+}$ spikes) have been well characterized in pyramidal neurons, where they require the activation of $N$-methyl-D-aspartate (NMDA) receptors, voltage-gated calcium channels (VGCCs), and $\mathrm{Na}^{+}$channels
(Schiller et al., 1997; Larkum et al., 1999; Golding et al., 2002; Losonczy and Magee, 2006). However, the mechanisms underlying $\mathrm{Ca}^{2+}$ spike initiation in distal dendrites of interneurons remain unknown.

In summary, despite the lack of the detailed information regarding the subcellular distribution of distinct ion conductances in different types of interneurons, at least two conclusions can be drawn from the findings reported so far. First, the distribution of active ion conductances may vary among different types of interneurons. Second, dependent on the density of voltagegated $\mathrm{Na}^{+} / \mathrm{Ca}^{2+}$ vs $\mathrm{K}^{+}$conductances, two distinct modes of synaptic integration may operate in interneuron dendrites: compartmentalized (different in proximal vs distal sites or within different dendritic branches) or relatively uniform. Accordingly, distinct types of interneurons will be differentially recruited by the inputs innervating different dendritic regions. Local finetuning via extrasynaptic mechanisms may provide additional ways for compartmentalized regulation of synaptic integration. In the following sections we will present the evidence for a compartmentalized regulation of interneuron dendritic conductances and synapse-specific plasticity by group I mGluRs.

\section{LOCAL BIOCHEMICAL SIGNALING VIA GROUP I mGluRs}

Depending on the level of activity, synaptic inputs can initiate various local biochemical reactions via the activation of synaptic and extrasynaptic signaling mechanisms. In different types of neurons, mGluRs represent the major extrasynaptic signaling platform that couple synaptic activity to various second messengers, including inositol-1,4,5-triphosphate $\left(\mathrm{IP}_{3}\right), \mathrm{Ca}^{2+}$, and cyclic adenosine monophosphate (cAMP). Group I mGluRs include two receptor subtypes, mGluR $1 \alpha$ and mGluR5, coupled both to the $\mathrm{G} \alpha_{\mathrm{q} / 11}$ G-protein subunit and to activation of phospholipase $\mathrm{C}, \mathrm{IP}_{3}$ production, and intracellular $\mathrm{Ca}^{2+}$ release (Pin and Duvoisin, 1995; Hermans and Challiss, 2001). In addition, the coupling of group I mGluRs to alternative cascades, such as cAMP-dependent release of arachidonic acid, has been reported (Aramori and Nakanishi, 1992). Group I mGluRs also partake in G-protein-independent signaling via Src-family tyrosine kinases (Heuss et al., 1999; Gee and Lacaille, 2004; Topolnik et al., 2006). For example, in hippocampal CA1 oriens/alveus (O/A) interneurons, activation of mGluR $1 \alpha$ triggers membrane depolarization and dendritic $\mathrm{Ca}^{2+}$ transients via a G-protein-independent mechanism involving the Src/extracellular signal-regulated kinase (ERK) cascade (Figure 1; Gee and Lacaille, 2004; Topolnik et al., 2006).

Many cell types coexpress mGluR $1 \alpha$ and mGluR5, whereas others exhibit specific patterns of distribution of these receptors. In hippocampal CA1 area, mGluR $1 \alpha$ is present in several distinct classes of interneurons with their somata located in strata pyramidale, radiatum, and lacunosum moleculare, whereas mGluR5 is expressed uniformly by many cell types (Baude et al., 1993; Lujan et al., 1996; Shigemoto et al., 1997; van Hooft et al., 2000; Ferraguti et al., 2004). However, mGluR1 $\alpha$ and mGluR5 may populate distinct dendritic sites (Topolnik et al., 2006). Differential group I mGluR expression was also found in layer IV of the somatosensory cortex, in fast-spiking and regularly spiking interneurons (Sun et al., 2009). Furthermore, using immunogold localization, group I mGluRs have been shown to concentrate in perisynaptic areas 


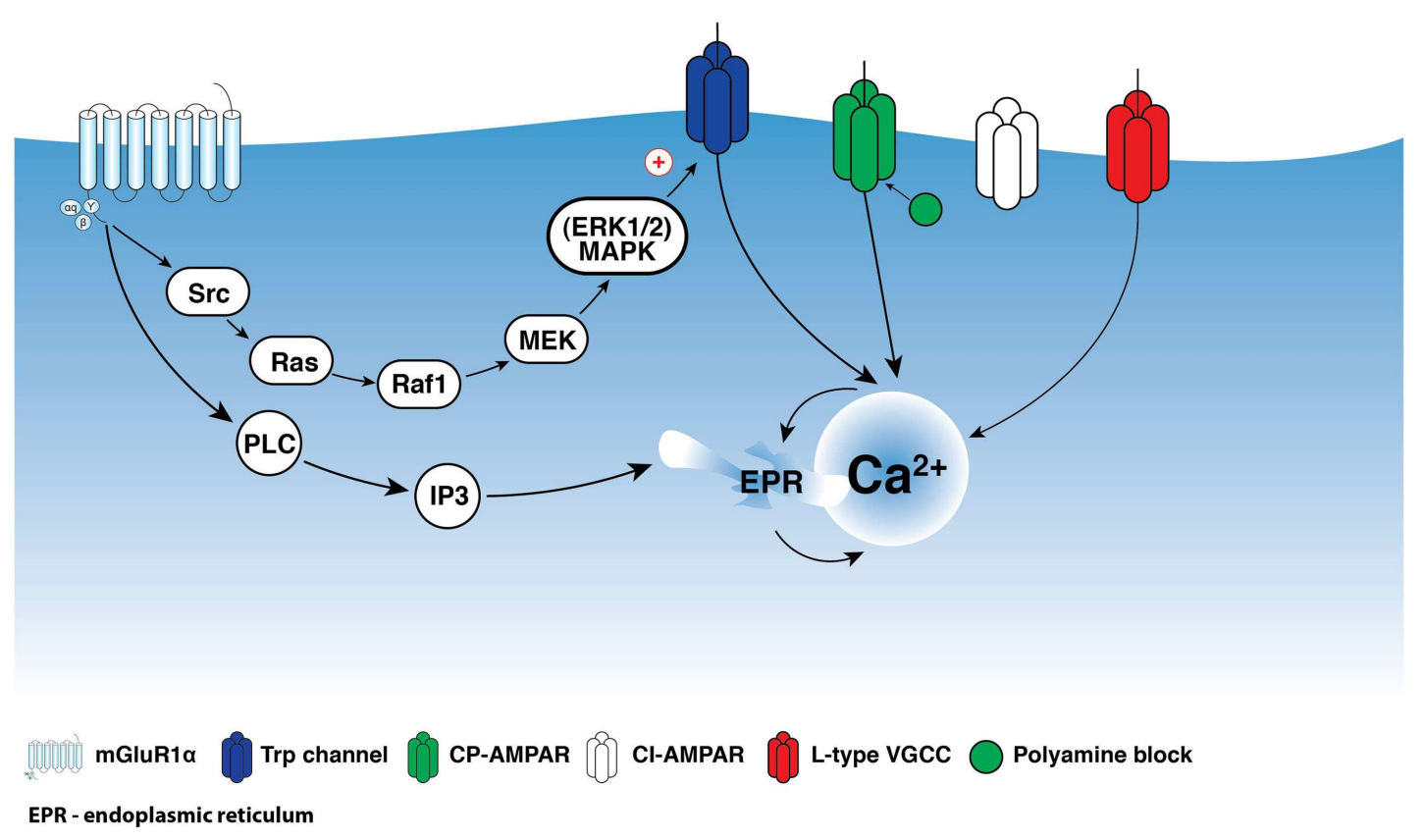

FIGURE 1 | Schematic representation of $m$ GluR1 $\alpha$ signaling in interneuron dendrites. Activation of $m G l u R 1 \alpha$ is coupled to two parallel signaling pathways: one leading to $\mathrm{Ca}^{2+}$ entry via TRP channels and a second producing $\mathrm{Ca}^{2+}$ release from intracellular stores. Src/ERK-cascade appears to be involved in the regulation of $\mathrm{Ca}^{2+}$ entry via TRP channels, which together with intracellular release are necessary for the induction of Hebbian LTP. In addition, mGluR $1 \alpha$ activation together with $\mathrm{Ca}^{2+}$ entry through CP-AMPARs appear to be involved in anti-Hebbian LTP induction. (surrounding synaptically located ionotropic receptors) in Purkinje cells (Nusser et al., 1994), hippocampal neurons (Baude et al., 1993; Lujan et al., 1996), neurons of the dorsal horn of the spinal cord (Vidnyánszky et al., 1994), and neurons of the subthalamic nucleus (Kuwajima et al., 2004). The subcellular localization of these receptors is controlled by their direct interaction with Homer proteins (Brakeman et al., 1997).

The recruitment of group I mGluRs depends on both preand post-synaptic activity. In hippocampal interneurons, highfrequency repetitive synaptic stimulation is required to evoke responses mediated by group I mGluRs (Topolnik et al., 2005). It has been demonstrated that the inhibition of the activity of astrocytic glutamate transporters, i.e., increase of the availability of extrasynaptic glutamate, facilitates $\mathrm{mGluR} 1 \alpha$ activation in hippocampal O/A interneurons (Huang et al., 2004). Interestingly, mGluR activation in interneurons is also achieved via synaptic stimulation paired with postsynaptic depolarization (Huang et al., 2004; Topolnik et al., 2005). Similar depolarization-dependent activation of mGluR-mediated responses has been shown in pyramidal neurons (Lüthi et al., 1997; Chuang et al., 2000; Rae et al., 2000; Rae and Irving, 2004). The mechanism responsible for the enhancement of mGluR responses through depolarization has yet to be identified in interneurons. The modulation of VGCCs or the activation of non-selective cation currents through the transientreceptor-potential (TRP) channels (Congar et al., 1997; Woodhall et al., 1999; Gee et al., 2003; Topolnik et al., 2006; Hartmann et al., 2008) may be associated with group I mGluR activation. In particular, some members of the canonical subfamily of TRP channels (TRPC1, TRPC4, TRPC5) show a similar voltage-dependence and high $\mathrm{Ca}^{2+}$ permeability and are likely to be activated by mGluR $1 \alpha$ (Topolnik et al., 2005, 2006).

A hallmark of group I mGluR activation is an increase in intracellular $\mathrm{Ca}^{2+}$ concentration resulting from intracellular $\mathrm{Ca}^{2+}$ release and/or $\mathrm{Ca}^{2+}$ influx through VGCCs or store-operated channels (Pin and Duvoisin, 1995; Hermans and Challiss, 2001). Depending on the cell type and the receptor subtype being activated, group I mGluR-induced intracellular $\mathrm{Ca}^{2+}$ elevations may exhibit different temporal properties, varying from plateau-like transient $\mathrm{Ca}^{2+}$ rises to $\mathrm{Ca}^{2+}$ oscillations. Overall, these $\mathrm{Ca}^{2+}$ signals are kinetically slow and may last several seconds. An exemption to this rule is the activation of mGluR $1 \alpha$ in O/A interneurons, where it is associated with a relatively fast $\mathrm{Ca}^{2+}$ response (Topolnik et al., 2005, 2006). Moreover, mGluR1 $\alpha /$ mGluR5mediated $\mathrm{Ca}^{2+}$ signals in these cells can be spatially restricted within individual dendritic branches and play distinct roles in local biochemical signaling (Topolnik et al., 2006). This is in contrast to pyramidal neurons, where group I mGluRs have been involved in the generation of traveling $\mathrm{Ca}^{2+}$ waves (Nakamura et al., 1999, 2002; Larkum et al., 2003; Hagenston et al., 2008).

Taken together, these data indicate that biochemical signaling via group I mGluRs is determined by the cell type, the receptor subtype distribution, the local interacting partners, and the conditions of the receptor activation. In interneurons, this signaling can be restricted within individual dendritic branches likely due to a local dendritic geometry and $\mathrm{Ca}^{2+}$ buffering. Therefore, in interneurons, group I mGluRs may be well positioned to control the immediate "voisinage" of activated synapses. 


\section{REGULATION OF DENDRITIC CONDUCTANCES VIA GROUP I mGluRs}

The activation of group I mGluRs has a profound effect on the state of ion conductances and on the input-output relationship. The modulation of VGCCs and $\mathrm{Na}^{+}$and $\mathrm{K}^{+}$channels, or channels that mediate non-selective cation currents, has been associated with group I mGluR activation in different cell types including interneurons (Congar et al., 1997; Woodhall et al., 1999; Gee et al., 2003; Huang et al., 2004; Carlier et al., 2006; Ramsey et al., 2006; Topolnik et al., 2006; Hartmann et al., 2008). In O/A interneurons, L-type VGCCs were functionally linked with mGluR5 and played a critical role in regulating the coupling between dendritic APs and $\mathrm{Ca}^{2+}$ (Topolnik et al., 2009). bAP-evoked $\mathrm{Ca}^{2+}$ entry into dendrites was enhanced for at least $30 \mathrm{~min}$ after the activation of mGluR5, but not mGluR1 $\alpha$ (Figure 2). This long-lasting increase in $\mathrm{bAP} \mathrm{Ca}{ }^{2+}$ signaling resulted from the potentiation of L-type VGCCs through $\mathrm{Ca}^{2+}$ release from ryanodine-sensitive stores and protein kinase $\mathrm{C}$ activation (Figure 3). Importantly, mGluR5 activation and bAP-CaTs potentiation were limited to $\sim 15 \mu \mathrm{m}$ of dendritic length (Figure 2D), enabling local boosting of bAP $\mathrm{Ca}^{2+}$ signaling with a potential effect on the induction of Hebbian long-term potentiation (LTP). A similar form of mGluR - L-type VGCC interaction - exists in cerebellar granule cells (Chavis et al., 1996), which suggests that this mechanism is not limited to $\mathrm{O} / \mathrm{A}$ interneurons. Such long-lasting potentiation of dendritic $\mathrm{Ca}^{2+}$ mechanisms is likely to have an effect on the activation of $\mathrm{Ca}^{2+}$-dependent $\mathrm{K}^{+}$channels, with consequences for local input integration and spike generation. Furthermore, several non-specific cation channels or members of the family of TRP channels can be activated by mGluR1 $\alpha$ in interneurons
(Figure 1; Topolnik et al., 2005, 2006). In addition to their role in synaptic plasticity (see below), these channels provide a persistent membrane depolarization in an input-specific manner, thus shaping local synaptic conductances and controlling the input-output relationship (Egorov et al., 2002).

Together with the highly compartmentalized modulation of dendritic conductances within particular dendritic domains, group I mGluRs may provide global control of information flow via the generation of propagating activity. For example, in pyramidal neurons, mGluR activation is associated with generation of spreading $\mathrm{Ca}^{2+}$ waves or regenerative $\mathrm{Ca}^{2+}$ events that can control neuronal firing (Larkum et al., 2003; Hagenston et al., 2008). This form of supralinear mGluR signaling is important for overall control of synaptic integration and dendrite-to-soma signaling, but remains to be identified in interneurons.

\section{GROUP I MGLURS AND SYNAPSE-SPECIFIC PLASTICITY}

Because the activation of group I mGluRs is associated with an increase in intracellular $\mathrm{Ca}^{2+}$ concentration, the involvement of these receptors in synaptic plasticity has been studied extensively. Several forms of synapse-specific plasticity, including LTP and long-term depression (LTD), that are dependent on group I mGluRs have been discovered at excitatory synapses of cortical interneurons. In a population of $\mathrm{O} / \mathrm{A}$ interneurons, a form of Hebbian LTP induced by pairing of theta-burst synaptic stimulation (TBS) with postsynaptic depolarization required activation of mGluR1 $\alpha$ (Perez et al., 2001; Lapointe et al., 2003; Croce et al., 2010). In addition, this form of LTP was initiated via pharmacological activation of either mGluR1 $\alpha$ or mGluR5, indicating the possible independent implication of the two receptors in the

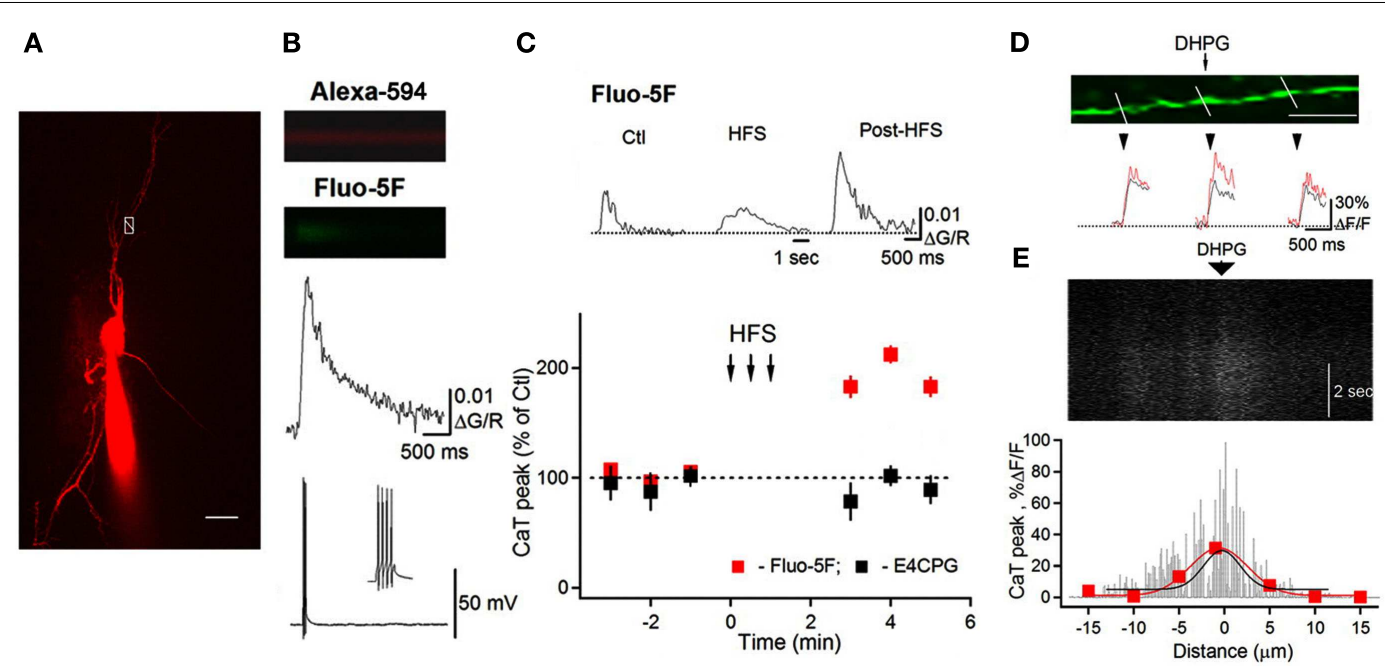

FIGURE 2 | Potentiation of bAP-CaTs in interneuron dendrites. (A) Two-photon image of an O/A interneuron filled with Alexa 594 and Fluo-5F. White box with a line across the dendrite indicate the position of the line scan to measure bAP-CaT shown in (B). Scale bar, $20 \mu \mathrm{m}$. (B) Line scan images and associated bAP-CaT. (C) Representative bAP-CaTs evoked before (Ctl) during (middle traces; HFS) and after high-frequency synaptic stimulation (post-HFS) within the same dendritic region, and a summary plot, indicating a significant post-HFS potentiation of bAP-CaTs. HFS-induced AP-CaT potentiation was prevented by the mGluR1/mGluR5 antagonist E4CPG. (D) Magnified image of a dendrite with lines indicating locations for bAP-CaT measurements. Scale bar, $10 \mu \mathrm{m}$. Traces below show bAP-CaTs obtained from these locations in control (black) and after DHPG application (100 $\mu \mathrm{M}$; red). (E) Line scan image collected along the middle part of the dendrite shown in (D) and demonstrating a slow DHPG $\mathrm{Ca}^{2+}$ response with corresponding spatial profile histogram (black fit). For comparison, the spatial profile of potentiated bAP-CaT (red) obtained from this region is shown superimposed. Modified from Topolnik et al. (2009) with permission. 


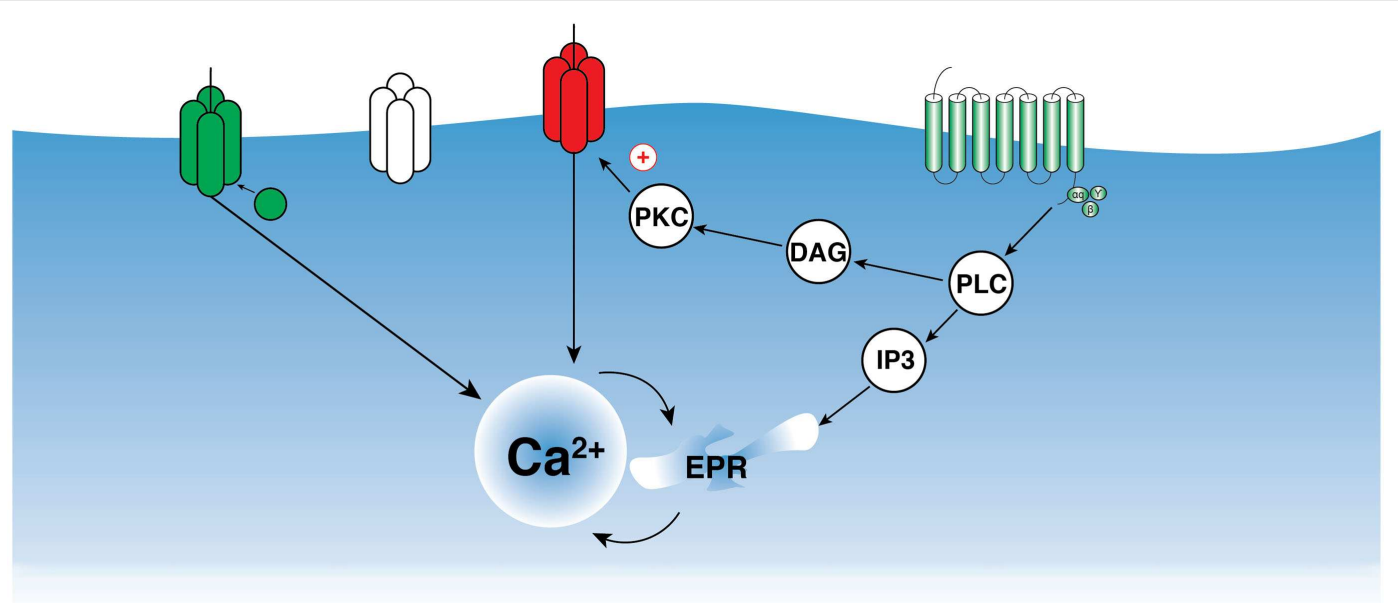

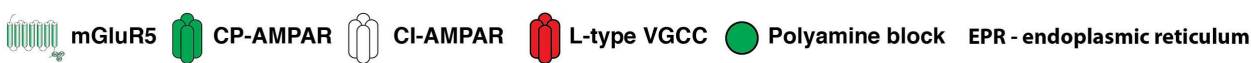

FIGURE 3 | Schematic representation of mGluR5 signaling in interneuron dendrites. Activation of mGluR5 may trigger phospholipase $\mathrm{C}(\mathrm{PLC})$ activation producing inositol-1,4,5-triphosphate $\left(\mathrm{IP}_{3}\right)$ and $\mathrm{Ca}^{2+}$ release from intracellular stores as well as diacylglycerol (DAG)/protein kinase $\mathrm{C}(\mathrm{PKC})$ activation. mGluR5-mediated $\mathrm{Ca}^{2+}$ release alone can be involved in LTD induction; however, together with $\mathrm{Ca}^{2+}$ entry through CP-AMPARs, mGluR5 appears to influence the induction of anti-Hebbian LTP. Moreover, mGluR5-dependent PKC activation produces persistent up-regulation of L-type VGCCs and may play a critical role in the regulation of Hebbian LTP. induction of this form of plasticity (Le Vasseur et al., 2008). In these cells, mGluR $1 \alpha$ activation led to an increase in intracellular $\mathrm{Ca}^{2+}$ via the activation of TRP channels and $\mathrm{Ca}^{2+}$-induced $\mathrm{Ca}^{2+}$ release from ryanodine-sensitive stores (Figure 1), whereas mGluR5 activation was coupled solely to $\mathrm{Ca}^{2+}$ release (Figure 3; Woodhall et al., 1999; Topolnik et al., 2006). Interestingly, a similar Hebbian TBS protocol induced LTP in interneurons of the visual cortex, but this LTP was mediated by mGluR5 and not by mGluR $1 \alpha$ (Sarihi et al., 2008). Furthermore, although these two examples of LTP required an increase in postsynaptic $\mathrm{Ca}^{2+}$, the fact that potentiation was expressed post-synaptically in neocortical interneurons and both pre- and post-synaptically in hippocampal interneurons suggests that these two forms of Hebbian plasticity engage distinct mechanisms.

In addition to the Hebbian form of synaptic plasticity, an anti-Hebbian LTP involving group I mGluRs was reported in a population of hippocampal interneurons (Lamsa et al., 2007; Le Duigou and Kullmann, 2011; Szabo et al., 2012). This LTP was induced by synaptic or pharmacological stimulation at hyperpolarized levels of membrane potential. The anti-Hebbian LTP required the activation of $\mathrm{Ca}^{2+}$-permeable $\alpha$-amino-3-hydroxy5-methyl-4-isoxazolepropionic acid receptors (CP-AMPARs) and of mGluR1 $\alpha$ and mGluR5 (Oren et al., 2009; Le Duigou and Kullmann, 2011). The involvement of group I mGluRs in antiHebbian LTP is surprising, as this would require significant excitation of interneurons at hyperpolarized levels of membrane potential. Although such conditions can be met in vivo, for example during sharp-wave-associated ripples when O-LM interneurons are silenced but receive a strong excitatory drive from CA1 pyramidal neurons (Klausberger et al., 2003), it is clear that additional mechanisms that are activated at hyperpolarized potentials are likely to cooperate with group I mGluRs during LTP induction. For example, a possible functional interaction may exist between CP-AMPARs and group I mGluRs, as both are located within the same dendritic microdomain (Topolnik et al., 2005). CP-AMPAR $\mathrm{Ca}^{2+}$ influx increases slightly with membrane hyperpolarization (Goldberg et al., 2003b; Topolnik et al., 2005), as the CP-AMPAR channel is blocked by endogenous polyamines at depolarizing potentials. Accordingly, mGluRinduced $\mathrm{Ca}^{2+}$ release at hyperpolarized levels of membrane potential can lower the threshold for LTP induction (Kullmann and Lamsa, 2007) by increasing the magnitude and duration of dendritic $\mathrm{Ca}^{2+}$ elevations. Similar functional interactions exist between mGluRs and TRP channels or VGCCs (Figures 1 and 3; Topolnik et al., 2006, 2009) and are involved in the induction of Hebbian plasticity, suggesting that, regardless of the stimulation paradigm, different $\mathrm{Ca}^{2+}$ mechanisms may converge on a common $\mathrm{Ca}^{2+}$-dependent signaling cascade, leading to LTP induction.

In addition to LTP, group I mGluRs play a role in the induction of LTD. In hippocampal stratum oriens and radiatum interneurons, application of the group I mGluR agonist (S)-DHPG at resting membrane potential resulted in synaptic depression, with mGluR $1 \alpha$ inducing reversible depression and mGluR5 inducing long-lasting depression (Le Duigou et al., 2011). In stratum radiatum interneurons, group I mGluR-dependent LTD was also induced by high-frequency synaptic stimulation (Gibson et al., 2008). This type of LTD is likely to be common for synapses formed by Schaffer collaterals, as it was also demonstrated in CA1 pyramidal neurons (Fitzjohn et al., 2001; Huber et al., 2001; Mannaioni et al., 2001). Group I mGluRs also control the direction of plasticity in interneurons. At excitatory synapses of lacunosummoleculare interneurons in hippocampal region Cornu Ammonis 3 (CA3), a protocol that induced Hebbian LTP also induced LTD 
if mGluR1 $\alpha$ was blocked (Galván et al., 2008). The two forms of plasticity required different levels of postsynaptic $\mathrm{Ca}^{2+}$ elevation. Whereas L-type VGCCs were involved in both LTP and LTD induction, mGluR $1 \alpha$-dependent $\mathrm{Ca}^{2+}$ release in conjunction with L-type VGCC activation was required for LTP. These data indicate that the polarity of plasticity in interneurons can be controlled by specific mGluR1 $\alpha$ - L-type VGCC interaction.

Taken together, these findings indicate that the implication of group I mGluRs in the induction of different forms of plasticity in interneurons varies according to the type of interneuron, the stimulation paradigm, the level of membrane potential, the receptor subtype that is activated, and the expression of ionotropic receptors and ion channels that may be part of the mGluR and synaptic compartment. It is worth mentioning that most of the forms of plasticity discussed above were expressed in part presynaptically, implying the group I mGluR-dependent activation of retrograde signaling via yet unknown mechanisms.

\section{CONCLUSION}

There is growing evidence that group I mGluRs play a critical role in the regulation of dendritic excitability and synaptic plasticity in

\section{REFERENCES}

Aponte, Y., Bischofberger, J., and Jonas, P. (2008). Efficient Ca2+ buffering in fast-spiking basket cells of rat hippocampus. J. Physiol. (Lond.) 586, 2061-2075.

Aramori, I., and Nakanishi, S. (1992). Signal transduction and pharmacological characteristics of a metabotropic glutamate receptor, mGluR1, in transfected CHO cells. Neuron 8, 757-765.

Bartos, M., Vida, I., and Jonas, P. (2007). Synaptic mechanisms of synchronized gamma oscillations in inhibitory interneuron networks. Nat. Rev. Neurosci. 8, 45-56.

Baude, A., Nusser, Z., Roberts, J. D., Mulvihill, E., McIlhinney, R. A., and Somogyi, P. (1993). The metabotropic glutamate receptor (mGluR1 alpha) is concentrated at perisynaptic membrane of neuronal subpopulations as detected by immunogold reaction. Neuron 11, 771-787.

Brakeman, P. R., Lanahan, A. A., O’Brien, R., Roche, K., Barnes, C. A., Huganir, R. L., and Worley, P. F. (1997). Homer: a protein that selectively binds metabotropic glutamate receptors. Nature 386, 284-288.

Branco, T., and Häusser, M. (2010). The single dendritic branch as a fundamental functional unit in the nervous system. Curr. Opin. Neurobiol. 20, 494-502.

Carlier, E., Sourdet, V., Boudkkazi, S., Déglise, P., Ankri, N., FronzaroliMolinieres, L., and Debanne, D. (2006). Metabotropic glutamate receptor subtype 1 regulates sodium currents in rat neocortical pyramidal neurons. J. Physiol. (Lond.) 577, 141-154.

Chavis, P., Fagni, L., Lansman, J. B., and Bockaert, J. (1996). Functional coupling between ryanodine receptors and L-type calcium channels in neurons. Nature 382, 719-722.

Chuang, S. C., Bianchi, R., and Wong, R. K. (2000). Group I mGluR activation turns on a voltage-gated inward current in hippocampal pyramidal cells. J. Neurophysiol. 83, 2844-2853.

Congar, P., Leinekugel, X., Ben-Ari, Y., and Crépel, V. (1997). A longlasting calcium-activated nonselective cationic current is generated by synaptic stimulation or exogenous activation of group I metabotropic glutamate receptors in CA1 pyramidal neurons. J. Neurosci. 17, 5366-5379.

Croce, A., Pelletier, J. G., Tartas, M., and Lacaille, J. C. (2010). Afferentspecific properties of interneuron synapses underlie selective long-term regulation of feedback inhibitory circuits in CA1 hippocampus. J. Physiol. (Lond.) 588, 2091-2107.

Egorov, A. V., Hamam, B. N., Fransén, E., Hasselmo, M. E., and Alonso, A. A. (2002). Graded persistent activity in entorhinal cortex neurons. Nature 420, 173-178.

Emri, Z., Antal, K., Gulyás, A. I., Megías, M., and Freund, T. F. (2001). Electrotonic profile and passive propagation of synaptic potentials in three subpopulations

interneurons. The two receptor subtypes (mGluR1 $\alpha$ and mGluR5) have cell type-specific distributions, can be activated by different patterns of synaptic activity, and, via coupling to distinct signaling cascades, can control specific cellular functions (Figures 1 and 3). In particular, mGluR1 $\alpha$ can interact with TRP channels, whereas mGluR5 is involved in L-type VGCC modulation, and both receptor subtypes may signal the induction of several forms of synaptic plasticity in interneurons. However, the extent to which the mechanisms activated by the two receptor subtypes are specific to particular types of interneurons, whether these mechanisms reflect the local circuit interactions, and whether they operate under natural conditions in vivo remain to be determined.

\section{ACKNOWLEDGMENTS}

This work was supported by the Canadian Institutes of Health Research, Natural Sciences and Engineering Research Council of Canada (NSERC Discovery Grant), Canadian Foundation for Innovation, Fonds de recherche du Québec - Santé, and Savoy Foundation. Lisa Topolnik is recipient of the University Faculty Award from NSERC. Jean-Claude Lacaille holds the Canada Research Chair in Cellular and Molecular Neurophysiology.

of hippocampal CA1 interneurons. Neuroscience 104, 1013-1026.

Evstratova, A., Chamberland, S., and Topolnik, L. (2011). Cell typespecific and activity-dependent dynamics of action potentialevoked $\mathrm{Ca} 2+$ signals in dendrites of hippocampal inhibitory interneurons. J. Physiol. (Lond.) 589, 1957-1977.

Ferraguti, F., Cobden, P., Pollard, M., Cope, D., Shigemoto, R., Watanabe, M., and Somogyi, P. (2004). Immunolocalization of metabotropic glutamate receptor 1alpha (mGluR1alpha) in distinct classes of interneuron in the CA1 region of the rat hippocampus. Hippocampus 14, 193-215.

Fitzjohn, S. M., Palmer, M. J., May, J. E., Neeson, A., Morris, S. A., and Collingridge, G. L. (2001). A characterisation of long-term depression induced by metabotropic glutamate receptor activation in the rat hippocampus in vitro. J. Physiol. (Lond.) 537, 421-430.

Frick, A., Magee, J., and Johnston, D. (2004). LTP is accompanied by an enhanced local excitability of pyramidal neuron dendrites. Nat. Neurosci. 7, 126-135.

Fricker, D., and Miles, R. (2000). EPSP amplification and the precision of spike timing in hippocampal neurons. Neuron 28, 559-569.

Galarreta, M., and Hestrin, S. (2001). Spike transmission and synchrony detection in networks of GABAergic interneurons. Science 292, 2295-2299.
Galván, E. J., Calixto, E., and Barrionuevo, G. (2008). Bidirectional Hebbian plasticity at hippocampal mossy fiber synapses on CA3 interneurons. J. Neurosci. 28, 14042-14055.

Gee, C. E., Benquet, P., and Gerber, U. (2003). Group I metabotropic glutamate receptors activate a calcium-sensitive transient receptor potential-like conductance in rat hippocampus. J. Physiol. (Lond.) 546, 655-664.

Gee, C. E., and Lacaille, J. C. (2004). Group I metabotropic glutamate receptor actions in oriens/alveus interneurons of rat hippocampal CA1 region. Brain Res. 1000, 92-101.

Geiger, J. R., Lübke, J., Roth, A., Frotscher, M., and Jonas, P. (1997). Submillisecond AMPA receptormediated signaling at a principal neuron-interneuron synapse. $\mathrm{Neu}$ ron 18, 1009-1023.

Gibson, H. E., Edwards, J. G., Page, R. S., Van Hook, M. J., and Kauer, J. A. (2008). TRPV1 channels mediate long-term depression at synapses on hippocampal interneurons. Neuron 57, 746-759.

Goldberg, J. H., Tamas, G., and Yuste, R. (2003a). Ca2+ imaging of mouse neocortical interneurone dendrites: Ia-type $\mathrm{K}+$ channels control action potential backpropagation. J. Physiol. (Lond.) 551, 49-65.

Goldberg, J. H., Yuste, R., and Tamas, G. (2003b). Calcium microdomains in aspiny dendrites. Neuron 13 , 807-821. 
Golding, N. L., Staff, N. P., and Spruston, N. (2002). Dendritic spikes as a mechanism for cooperative long-term potentiation. Nature 418, 326-331.

Goldstein, S. S., and Rall, W. (1974). Changes of action potential shape and velocity for changing core conductor geometry. Biophys. J. 14, 731-757.

Gulyás, A. I., Megías, M., Emri, Z., and Freund, T. F. (1999). Total number and ratio of excitatory and inhibitory synapses converging onto single interneurons of different types in the CA1 area of the rat hippocampus. J. Neurosci. 19, 10082-10097.

Hagenston, A. M., Fitzpatrick, J. S., and Yeckel, M. F. (2008). MGluRmediated calcium waves that invade the soma regulate firing in layer $\mathrm{V}$ medial prefrontal cortical pyramidal neurons. Cereb. Cortex 18, 407-423.

Hartmann, J., Dragicevic, E., Adelsberger, H., Henning, H. A., Sumser, M., Abramowitz, J., Blum, R., Dietrich, A., Freichel, M., Flockerzi, V., Birnbaumer, L., and Konnerth, A. (2008). TRPC3 channels are required for synaptic transmission and motor coordination. Neuron 59, 392-398.

Hermans, E., and Challiss, R. A. (2001). Structural, signalling and regulatory properties of the group I metabotropic glutamate receptors: prototypic family C G-proteincoupled receptors. Biochem. J. 359, 465-484.

Heuss, C., Scanziani, M., Gähwiler, B. H., and Gerber, U. (1999). G-protein-independent signaling mediated by metabotropic glutamate receptors. Nat. Neurosci. 2, 1070-1077.

$\mathrm{Hu}, \mathrm{H}$., Martina, M., and Jonas, P. (2010). Dendritic mechanisms underlying rapid synaptic activation of fast-spiking hippocampal interneurons. Science 327, 52-58.

Huang, Y. H., Sinha, S. R., Tanaka, K., Rothstein, J. D., and Bergles, D. E. (2004). Astrocyte glutamate transporters regulate metabotropic glutamate receptor-mediated excitation of hippocampal interneurons. J. Neurosci. 24, 4551-4559.

Huber, K. M., Roder, J. C., and Bear, M. F. (2001). Chemical induction of mGluR5- and protein synthesisdependent long-term depression in hippocampal area CA1. J. Neurophysiol. 86, 321-325.

Kaiser, K. M., Zilberter, Y., and Sakmann, B. (2001). Back-propagating action potentials mediate calcium signalling in dendrites of bitufted interneurons in layer $2 / 3$ of rat somatosensory cortex. J. Physiol. (Lond.) 535, 17-31.

Klausberger, T., Magill, P. G., Marton, L. F., Roberts, J. D., Cobden, P. M., Buzsaki, G., and Somogyi, P. (2003). Brain state- and cell type-specific firing of hippocampal interneurons in vivo. Nature 421, 844-848.

Kullmann, D. M., and Lamsa, K. P. (2007). Long-term synaptic plasticity in hippocampal interneurons. Nat. Rev. Neurosci. 8, 687-699.

Kuwajima, M., Hall, R. A., Aiba, A., and Smith, Y. (2004). Subcellular and subsynaptic localization of group I metabotropic glutamate receptors in the monkey subthalamic nucleus. J. Comp. Neurol. 474, 589-602.

Lamsa, K. P., Heeroma, J. H., Somogyi, P., Rusakov, D. A., and Kullmann, D. M. (2007). Anti-Hebbian longterm potentiation in the hippocampal feedback inhibitory circuit. Science 315, 1262-1266.

Lapointe, V., Morin, F., Ratté, S., Croce, A., Conquet, F., and Lacaille, J. C. (2003). Synapse-specific mGluR1dependent long-term potentiation in interneurones regulates mouse hippocampal inhibition. J. Physiol. (Lond.) 555, 125-135.

Larkum, M. E., Kaiser, K. M., and Sakmann, B. (1999). Calcium electrogenesis in distal apical dendrites of layer 5 pyramidal cells at a critical frequency of back-propagating action potentials. Proc. Natl. Acad. Sci. U.S.A. 96, 14600-14604.

Larkum, M. E., Watanabe, S., Nakamura, T., Lasser-Ross, N., and Ross, W. N. (2003). Synaptically activated $\mathrm{Ca} 2+$ waves in layer $2 / 3$ and layer 5 rat neocortical pyramidal neurons. $J$. Physiol. (Lond.) 549, 471-488.

Le Duigou, C., Holden, T., and Kullmann, D. M. (2011). Shortand long-term depression at glutamatergic synapses on hippocampal interneurons by group I mGluR activation. Neuropharmacology 60, 748-756.

Le Duigou, C., and Kullmann, D. M. (2011). Group I mGluR agonistevoked long-term potentiation in hippocampal oriens interneurons. J. Neurosci. 31, 5777-5781.

Le Vasseur, M., Ran, I., and Lacaille, J. C. (2008). Selective induction of metabotropic glutamate receptor 1and metabotropic glutamate receptor 5-dependent chemical longterm potentiation at oriens/alveus interneuron synapses of mouse hippocampus. Neuroscience 151, 28-42.

Losonczy, A., and Magee, J. C. (2006). Integrative properties of radial oblique dendrites in hippocampal
CA1 pyramidal neurons. Neuron 50, 291-307.

Lujan, R., Nusser, Z., Roberts, J. D., Shigemoto, R., and Somogyi, P. (1996). Perisynaptic location of metabotropic glutamate receptors mGluR1 and mGluR5 on dendrites and dendritic spines in the rat hippocampus. Eur. J. Neurosci. 8, 1488-1500.

Lüthi, A., Gähwiler, B. H., and Gerber, U. (1997). 1S, 3R-ACPD induces a region of negative slope conductance in the steady-state currentvoltage relationship of hippocampal pyramidal cells. J. Neurophysiol. 77, 221-228.

Mannaioni, G., Marino, M. J., Valenti, O., Traynelis, S. F., and Conn, P. J. (2001). Metabotropic glutamate receptors 1 and 5 differentially regulate CA1 pyramidal cell function. $J$. Neurosci. 21, 5925-5934.

Martina, M., Vida, I., and Jonas, P. (2000). Distal initiation and active propagation of action potentials in interneuron dendrites. Science 287, 295-300.

Nakamura, T., Barbara, J. G., Nakamura, K., and Ross, W. N. (1999). Synergistic release of $\mathrm{Ca} 2+$ from IP3sensitive stores evoked by synaptic activation of mGluRs paired with backpropagating action potentials Neuron 24, 727-737.

Nakamura, T., Lasser-Ross, N., Nakamura, K., and Ross, W. N. (2002). Spatial segregation and interaction of calcium signalling mechanisms in rat hippocampal CA1 pyramidal neurons. J. Physiol. (Lond.) 543 465-480.

Nistri, A., Ostroumov, K., Sharifullina, E., and Taccola, G. (2006). Tuning and playing a motor rhythm: how metabotropic glutamate receptors orchestrate generation of motor patterns in the mammalian central nervous system. J. Physiol. (Lond.) 572, 323-334.

Nörenberg, A., Hu, H., Vida, I., Bartos, M., and Jonas, P. (2010). Distinct nonuniform cable properties optimize rapid and efficient activation of fast-spiking GABAergic interneurons. Proc. Natl. Acad. Sci. U.S.A. 107, 894-899.

Nusser, Z., Mulvihill, E., Streit, P. and Somogyi, P. (1994). Subsynaptic segregation of metabotropic and ionotropic glutamate receptors as revealed by immunogold localization. Neuroscience 61 , 421-427.

Oren, I., Nissen, W., Kullmann, D. M., Somogyi, P., and Lamsa, K. P. (2009). Role of ionotropic glutamate receptors in long-term potentiation in rat hippocampal CA1 orienslacunosum moleculare interneurons. J. Neurosci. 29, 939-950.

Perez, Y., Morin, F., and Lacaille, J. C. (2001). A Hebbian form of longterm potentiation dependent on mGluRla in hippocampal inhibitory interneurons. Proc. Natl. Acad. Sci. U.S.A. 98, 9401-9406.

Pin, J. P., and Duvoisin, R. (1995). The metabotropic glutamate receptors: structure and functions. Neuropharmacology 34, 1-26.

Rae, M. G., and Irving, A. J. (2004). Both mGluR1 and mGluR5 mediate $\mathrm{Ca} 2+$ release and inward currents in hippocampal CAl pyramidal neurons. Neuropharmacology 46, 1057-1069.

Rae, M. G., Martin, D. J., Collingridge, G. L., and Irving, A. J. (2000). Role of $\mathrm{Ca} 2+$ stores in metabotropic Lglutamate receptor-mediated supralinear $\mathrm{Ca} 2+$ signaling in rat hippocampal neurons. J. Neurosci. 20, 8628-8636.

Rall, W. (1964). “Theoretical significance of dendritic trees for neuronal input-output relations," in Neural Theory and Modeling, ed. R. F. Reiss (Stanford, CA: Stanford University Press), 73-97.

Ramón y Cajal, S. (1891). Sur la structure de l'ecorce cerebrale de quelques mamiferes. Cellule 7, 124-176.

Ramsey, I. S., Delling, M., and Clapham, D. E. (2006). An introduction to TRP channels. Annu. Rev. Physiol. 68, 619-647.

Ribeiro, F. M., Paquet, M., Cregan, S. P., and Ferguson, S. S. (2010). Group I metabotropic glutamate receptor signaling and its implication in neurological disease. CNS Neurol. Disord. Drug Targets 9, 574-595.

Sabatini, B. L., Oertner, T. G., and Svoboda, K. (2002). The life cycle of $\mathrm{Ca}(2+)$ ions in dendritic spines. Neuron 31, 439-452.

Sarihi, A., Jiang, B., Komaki, A., Sohya, K., Yanagawa, Y., and Tsumoto, T. (2008). Metabotropic glutamate receptor type 5-dependent longterm potentiation of excitatory synapses on fast-spiking GABAergic neurons in mouse visual cortex. $J$. Neurosci. 28, 1224-1235.

Schiller, J., Schiller, Y., Stuart, G., and Sakmann, B. (1997). Calcium action potentials restricted to distal apical dendrites of rat neocortical pyramidal neurons. J. Physiol. (Lond.) 505, 605-616.

Shigemoto, R., Kinoshita, A., Wada, E., Nomura, S., Ohishi, H., Takada, M., Flor, P. J., Neki, A., Abe, T., Nakanishi, S., and Mizuno, N. (1997). Differential presynaptic localization 
of metabotropic glutamate receptor subtypes in the rat hippocampus. $J$. Neurosci. 17, 7503-7522.

Sjöström, P. J., and Häusser, M. (2006). A cooperative switch determines the sign of synaptic plasticity in distal dendrites of neocortical pyramidal neurons. Neuron 51, 227-238.

Spruston, N., Schiller, Y., Stuart, G., and Sakmann, B. (1995). Activitydependent action potential invasion and calcium influx into hippocampal CA1 dendrites. Science 268, 297-300.

Stuart, G. J., and Sakmann, B. (1994). Active propagation of somatic action potentials into neocortical pyramidal cell dendrites. Nature 367, 69-72.

Sun, Q. Q., Zhang, Z., Jiao, Y., Zhang, C., Szabó, G., and Erdelyi, F. (2009). Differential metabotropic glutamate receptor expression and modulation in two neocortical inhibitory networks. J. Neurophysiol. 101, 2679-2692.

Szabo, A., Somogyi, J., Cauli, B., Lambolez, B., Somogyi, P., and Lamsa, K. P. (2012). Calcium-permeable
AMPA receptors provide a common mechanism for LTP in glutamatergic synapses of distinct hippocampal interneuron types. J. Neurosci. 32, 6511-6516.

Topolnik, L., Azzi, M., Morin, F., Kougioumoutzakis, A., and Lacaille, J. C. (2006). mGluR1/5 subtype-specific calcium signalling and induction of long-term potentiation in rat hippocampal oriens/alveus interneurones. J. Physiol. (Lond.) 575, 115-131.

Topolnik, L., Chamberland, S., Pelletier, J. G., Ran, I., and Lacaille, J. C. (2009). Activity-dependent compartmentalized regulation of dendritic $\mathrm{Ca} 2+$ signaling in hippocampal interneurons. J. Neurosci. 29, 4658-4663.

Topolnik, L., Congar, P., and Lacaille, J. C. (2005). Differential regulation of metabotropic glutamate receptorand AMPA receptor-mediated dendritic $\mathrm{Ca} 2+$ signals by presynaptic and postsynaptic activity in hippocampal interneurons. J. Neurosci. 25, 990-1001.

Topolnik, L., and Lacaille, J. C. (2009). "Functional reorganization of inhibitory circuits in epilepsy: mGluR1/5 signaling mechanisms and long-term plasticity," in Encyclopedia of Basic Epilepsy Research, ed. P. Schwartzkroin (Elsevier), 424-429.

van Hooft, J. A., Giuffrida, R., Blatow, M., and Monyer, H. (2000). Differential expression of group I metabotropic glutamate receptors in functionally distinct hippocampal interneurons. J. Neurosci. 20, 3544-3551.

Vetter, P., Roth, A., and Häusser, M. (2001). Propagation of action potentials in dendrites depends on dendritic morphology. J. Neurophysiol. 85, 926-937.

Vidnyánszky, Z., Hámori, J., Négyessy, L., Rüegg, D., Knöpfel, T., Kuhn, R., and Görcs, T. J. (1994). Cellular and subcellular localization of the mGluR5a metabotropic glutamate receptor in rat spinal cord. Neuroreport 6, 209-213.

Woodhall, G., Gee, C. E., Robitaille, R. and Lacaille, J. C. (1999). Membrane potential and intracellular $\mathrm{Ca} 2+$ oscillations activated by mGluRs in hippocampal stratum oriens/alveus interneurons. J. Neurophysiol. 81, 371-382.

Conflict of Interest Statement: The authors declare that the research was conducted in the absence of any commercial or financial relationships that could be construed as a potential conflict of interest.

Received: 01 April 2012; accepted: 21 June 2012; published online: 09 July 2012.

Citation: Camiré O, Lacaille J-C and Topolnik L (2012) Dendritic signaling in inhibitory interneurons: local tuning via group I metabotropic glutamate receptors. Front. Physio. 3:259. doi: 10.3389/fphys.2012.00259

This article was submitted to Frontiers in Membrane Physiology and Biophysics, a specialty of Frontiers in Physiology. Copyright (c) 2012 Camiré, Lacaille and Topolnik. This is an open-access article distributed under the terms of the Creative Commons Attribution License, which permits use, distribution and reproduction in other forums, provided the original authors and source are credited and subject to any copyright notices concerning any third-party graphics etc. 